Original

\title{
Development of Quantitative Duplex Real-Time PCR Method for Screening Analysis of Genetically Modified Maize
}

(Received October 31, 2008)

\author{
Taichi OGuChI ${ }^{1,}{ }^{\dagger}$, Mari Onishi ${ }^{2}$, Yasutaka Minegishi ${ }^{3}$, Yasunori Kurosawa ${ }^{1}$, \\ Masaki Kasahara ${ }^{1,4}$, Hiroshi Akiyama ${ }^{5}$, Reiko Teshima ${ }^{5}$, Satoshi Futo ${ }^{2}$, \\ Satoshi Furui ${ }^{1}$, Akihiro Hino ${ }^{1}$ and Kazumi Kitta ${ }^{1, *}$ \\ ${ }^{1}$ Analytical Science Division, National Food Research Institute, National Agriculture \\ and Food Research Organization: 2-1-12 Kannnondai, \\ Tsukuba, Ibaraki 305-8642, Japan \\ ${ }^{2}$ Fasmac Co., Ltd.: 5-1-3 Midorigaoka, Atsugi, Kanagawa 243-0041, Japan \\ ${ }^{3}$ Nippon Gene Co., Ltd.: 1-8-7 Toiyamachi, Toyama, Toyama 930-0834, Japan \\ ${ }^{4}$ Food and Agricultural Materials Inspection Center: \\ 2-1 Shintoshin, Chuo-ku, Saitama, Saitama 330-9731, Japan \\ ${ }^{5}$ National Institute of Health Sciences: 1-81-1 Kamiyoga, Setagaya-ku, Tokyo 158-8501, Japan \\ ${ }^{\dagger}$ Present address: National Institute of Agribiological Sciences: 2-1-2 Kannnondai, \\ Tsukuba, Ibaraki 305-8602, Japan; ${ }^{*}$ Corresponding author
}

\begin{abstract}
A duplex real-time PCR method was developed for quantitative screening analysis of GM maize. The duplex real-time PCR simultaneously detected two GM-specific segments, namely the cauliflower mosaic virus (CaMV) 35S promoter (P35S) segment and an event-specific segment for GA21 maize which does not contain P35S. Calibration was performed with a plasmid calibrant specially designed for the duplex PCR. The result of an in-house evaluation suggested that the analytical precision of the developed method was almost equivalent to those of simplex real-time PCR methods, which have been adopted as ISO standard methods for the analysis of GMOs in foodstuffs and have also been employed for the analysis of GMOs in Japan. In addition, this method will reduce both the cost and time requirement of routine GMO analysis by half. The high analytical performance demonstrated in the current study would be useful for the quantitative screening analysis of GM maize. We believe the developed method will be useful for practical screening analysis of GM maize, although interlaboratory collaborative studies should be conducted to confirm this.
\end{abstract}

Key words: genetically modified (GM); maize (Zea mays); duplex real-time PCR

\section{Introduction}

Recombinant DNA (r-DNA) technologies have been used in modern farming and have provided many advantages in related industries. In fact, the global area of genetically modified (GM) crops exceeded 120 million hectares in 2007, and is expected to continue to rise ${ }^{1)}$. GM crops have been authorized for use as food and/or feed in many countries based on each country's own criteria for safety assessment. However, consumers have demanded appropriate information and labeling for foods derived from GM crops. Thus, various labeling systems have been introduced for GM foods in the European Union (EU)*1, Korea*2, Japan*3,*4, and other countries (reviewed by $\mathrm{Hino}^{2)}$ ). In addition, many countries have found ways for the farming of conventional crops and GM crops to coexist. In these situations, the growing importance of scientific GM detection methods has been recognized.
For the detection of GM maize in foods and food materials, PCR-based detection methods, which are able to detect even small amounts of transgenes in raw materials and processed foods, have been routinely used $^{3)-5)}$. We have also developed simplex and multiplex qualitative PCR methods ${ }^{6)-11}$, simplex real-time PCR methods ${ }^{12), 13)}$, and an individual kernel-based detection method including a qualitative multiplex real-time $\mathrm{PCR}^{14)}$. In particular, six real-time PCR methods for five events of GM maize, i.e., Bt11, Bt176, GA21, MON810,

\footnotetext{
${ }^{* 1}$ Regulation (EC) No. 1829/2003. Official J. Eur. Union L268, 1-23 (2003).

*2 Notification No. 2000-31; Ministry of Agriculture and Forestry of Korea (2000).

*3 Notification No. 110 (Mar. 27, 2001); Department of Food Safety, Ministry of Health, Labour and Welfare of Japan (2001).

*4 Notification No. 517 (Mar. 31, 2000); Ministry of Agriculture, Forestry and Fisheries of Japan (2000).
} 
and T25, and a Roundup Ready soy, were fully validated by an international interlaboratory collaborative study ${ }^{12)}{ }^{15)}$, and have been not only employed as Japanese official analytical methods ${ }^{* 3}, * 4$, but also internationally recognized as ISO standard methods for the analysis of GMOs in foodstuffs*5. On the other hand, the cost and time required for GM analysis could constitute a major bottleneck in the process of providing consumers with cost-effective labeling ${ }^{16}$. The conventional or non-GM food supply chains, however, must be secured by affordable detection methods. Thus, the development of cost- and time-effective detection methods is important to ensure freedom of choice for consumers.

Maize is the major agricultural crop to which GM technology has been applied. In Japan, sixteen events of GM maize and twenty varieties of their hybrid progenies have been authorized as of $2008^{* 6}$, and in fact, some of them, e.g., Bt11, Bt176, GA21, MON810, MON 863, NK603, T25 and TC1506, have been used for commercial purposes in Japan. Analysis of the r-DNA constructions of these eight GM maize events elucidated that all the events except GA21 maize contained the same constitutive promoter, which originated from the cauliflower mosaic virus (CaMV) and has been designated as CaMV35S promoter (P35S). The Ministry of Health, Labour and Welfare of Japan (MHLW) announced a combinational method for the quantitation of P35S and a construct-specific quantitation for GA21 maize, and it has been officially used as a screening method for GM maize ${ }^{12), 33 * 4}$, though it requires two independent quantitations. Thus, to improve the efficiency of the GM analysis method, we have been trying to develop a screening analytical method for GM maize based on our real-time PCR methodologies. In this study, we developed a duplex real-time PCR method for simultaneous quantitation of both P35S and an eventspecific sequence for GA21 maize, and evaluated the performance characteristics of the newly developed method by means of a single-laboratory validation procedure.

\section{Materials and Methods}

\section{Maize (Zea mays) and other plant materials}

Dry seeds of GM maize, i.e., one progeny each of Bt11 and Event176 developed by Syngenta Seeds AG (Basel, Switzerland), a progeny of TC1507 developed by Dow Agrosciences LLC (Indianapolis, IN, USA), one progeny each of MON810, MON863, GA21, and NK603 developed by Monsanto Company (St. Louis, MO, USA) were provided by their respective developers, and a progeny of T25 developed by Bayer CropScience AG (Monheim am Rhein, Germany) was directly imported from the USA. Dry seeds of QC9651 maize (Quality

\footnotetext{
${ }^{* 5}$ Foodstuffs - methods of analysis for the detection of genetically modified organisms and derived products - quantitative nucleic acid based methods, Annex of ISO 21570: 2005 (2005).

*6 http://www.mhlw.go.jp/english/topics/food/pdf/sec01-2. pdf
}

Technology International, Inc., Elgy, IL, USA) were used as a non-GM control. Dry seeds of Roundup Ready $^{\circledR}(\mathrm{RR})$ soy, and non-GM cereal materials, i.e., dry soybeans harvested in Ohio in 1998, rice (Oryza sativa) variety Kinuhikari, wheat (Triticum aestivum) variety Haruyutaka, and barley (Hordeum vulgare) variety Harrington (these were harvested in Japan) were used as experimental controls.

\section{DNA extraction}

Maize and other plant seed materials were ground with a P-14 seed rotor mill (Fritsch GmbH, IbarOberstein, Germany) and used for DNA extraction. DNA extraction was performed with the DNeasy Plant Maxi kit (QIAGEN GmbH, Hilden, Germany) as described in our previous report ${ }^{12}$. The DNA concentration of solutions was determined by measuring UV absorption at $260 \mathrm{~nm}$, and the quality of DNA solutions was evaluated in terms of the absorption ratios at $260 / 280 \mathrm{~nm}$ and $260 / 230 \mathrm{~nm}$. DNA solutions whose absorption ratios were between 1.7 and 2.0 at 260/280 $\mathrm{nm}$ and were $>1.7$ at $260 / 230 \mathrm{~nm}$ were used for the subsequent experiments.

\section{Oligonucleotide primers and probes}

The primer pairs and TaqMan ${ }^{\circledR}$ probes used in this study are listed in Table 1 . The primers were synthesized by Fasmac Co., Ltd. (Kanagawa, Japan) and purified by HPLC. TaqMan probes with a carboxytetramethylrhodamine (TAMRA) quencher and with a Blackhole Quencher (BHQ) were synthesized by Applied Biosystems, Inc. (Foster City, CA, USA) and Biosearch Technologies, Inc. (Novato, CA, USA), respectively. Each oligonucleotide was diluted to the appropriate concentration for real-time PCR assays with sterilized water and stored at $-30^{\circ} \mathrm{C}$ until use.

\section{Qualitative PCR conditions}

A $25 \mu \mathrm{L}$ reaction solution contained $25 \mathrm{ng}$ genomic DNA, $0.2 \mathrm{mmol} / \mathrm{L} \mathrm{dNTP,} 1.5 \mathrm{mmol} / \mathrm{L} \mathrm{MgCl}_{2}, 0.5 \mu \mathrm{mol} / \mathrm{L}$ of each of the primers, and 0.625 units of AmpliTaq Gold DNA polymerase (Applied Biosystems). The reactions were buffered with PCR buffer II (Applied Biosystems) and amplified in a thermal cycler, the Silver 96-Well GeneAmp PCR System 9700 (Applied Biosystems) in Max mode, according to the following step-cycle program: pre-incubation at $95^{\circ} \mathrm{C}$ for $10 \mathrm{~min}$; 40 cycles consisting of denaturation at $95^{\circ} \mathrm{C}$ for $0.5 \mathrm{~min}$, annealing at $60^{\circ} \mathrm{C}$ for $1 \mathrm{~min}$ and extension at $72^{\circ} \mathrm{C}$ for 1 min; followed by a final extension at $72^{\circ} \mathrm{C}$ for $7 \mathrm{~min}$. The PCR products were analyzed by agarose gel electrophoresis buffered with $1 \times$ Tris-Acetate-EDTA (TAE) solution.

\section{Real-time PCR condition and calculation of GM contents}

In general, the experimental conditions of real-time PCRs followed those of our previous methods ${ }^{12)}$, which have been employed as the Japanese official method and the ISO standard method for GM detection*3-*5. A 


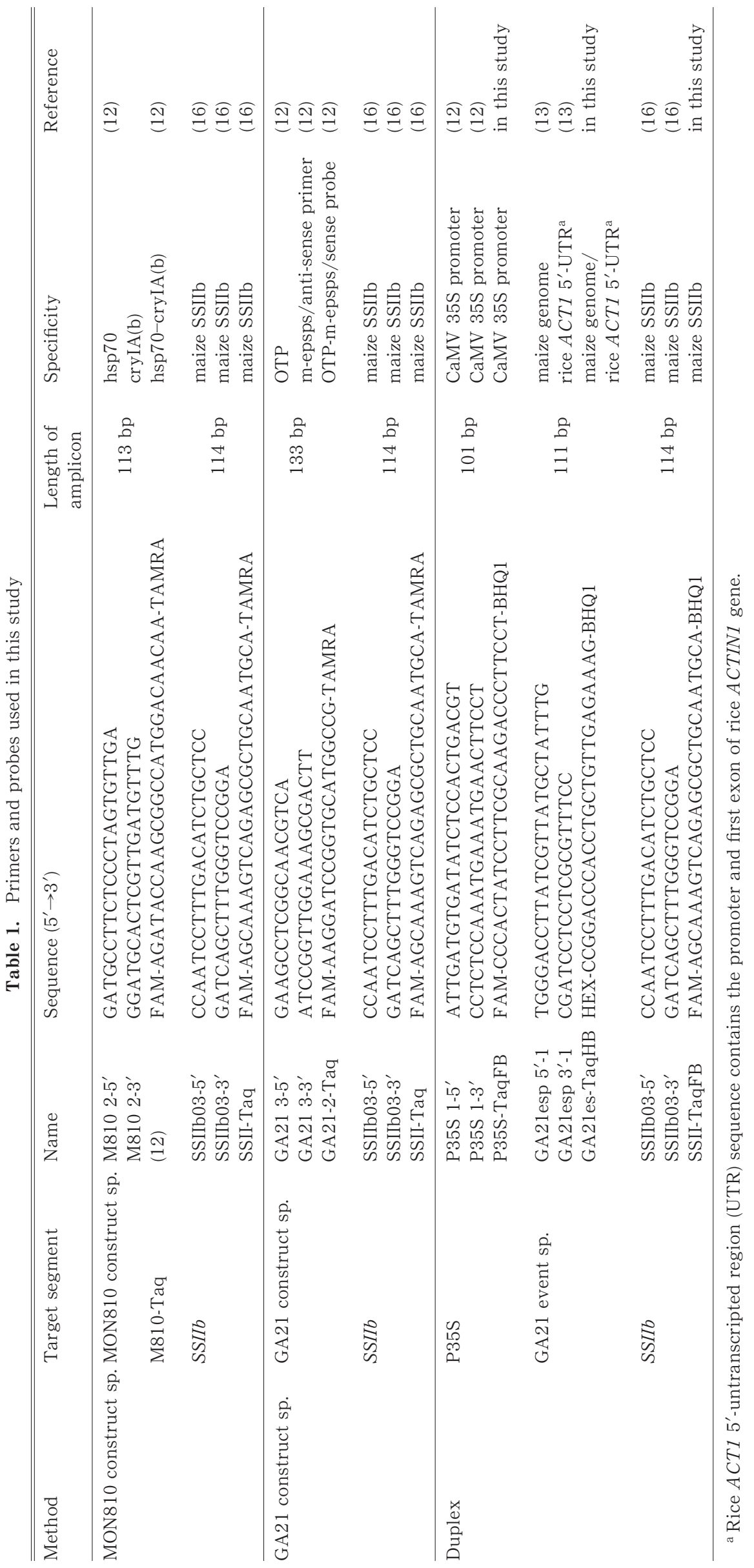




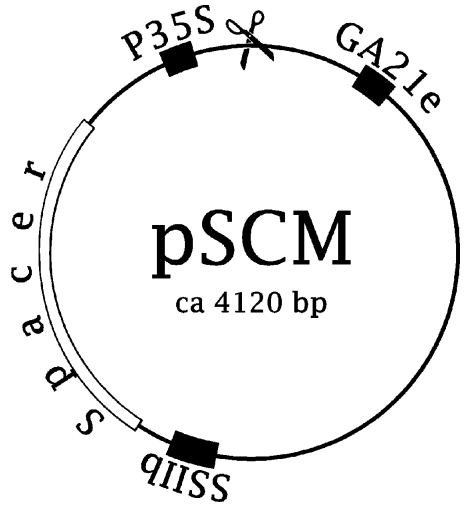

Fig. 1. Schematic illustration of plasmid, designated pSCM, for calibration of duplex real-time PCR

The filled boxes indicate cloned segments including each of the amplification targets. The open box indicates the spacer derived from lambda phase DNA. The pSCM plasmid was digested on the site indicated with a scissor symbol and used for calibration.

$25 \mu \mathrm{L}$ reaction solution for the duplex real-time PCR contained $1 \times$ Universal Master Mix (Applied Biosystems), $50 \mathrm{ng}$ genomic DNA as a template, 0.5 $\mu \mathrm{mol} / \mathrm{L}$ of each of the primers, and $0.1 \mu \mathrm{mol} / \mathrm{L}$ of each of the TaqMan ${ }^{\circledR}$ probes. The duplex real-time PCR was performed with the 7900 real-time PCR system or the 7500 real-time PCR system (Applied Biosystems), and all reactions were performed with the 9600 emulation mode and the following step-cycle program: preincubation at $50^{\circ} \mathrm{C}$ for $2 \mathrm{~min}$ and $90^{\circ} \mathrm{C}$ for $10 \mathrm{~min}, 45$ cycles consisting of denaturation at $95^{\circ} \mathrm{C}$ for $0.5 \mathrm{~min}$ and annealing and extension at $59^{\circ} \mathrm{C}$ for $1 \mathrm{~min}$. Each amplification was performed in parallel in three wells, unless otherwise described.

For the analytical calibration, a dilution series of the plasmid was employed in this study (Fig. 1). The plasmid was extracted from bacterial bulk culture using the QIAGEN ${ }^{\circledR}$ plasmid Mega kit (QIAGEN) and linearized by restriction digestion at sites located outside of the inserted segments. The linearized plasmid DNA was purified by $\mathrm{CsCl}$ ultracentrifugation and diluted with TE buffer, including $5 \mathrm{ng} / \mu \mathrm{L}$ of ColE1 plasmid, to five different concentrations, i.e., 20, 125, 1,500, 20,000, and 250,000 copies per $2.5 \mu \mathrm{L}$, based on the copy numbers of the maize starch synthase IIb gene (SSIIb) segment.

The GM contents of the samples were calculated from the proportion of the copy number of the GM-specific segment to that of the taxonomic marker for maize, SSIIb, by the following formula:

GM content (\%)

$$
\begin{aligned}
= & \frac{\text { Copy number of GM-specific segment }}{\text { Copy number of taxonomic marker }} \\
& \times \frac{1}{C_{\mathrm{f}}} \times 100 .
\end{aligned}
$$

The real-time PCRs for the quantitation of the copy numbers of the GM-specific segment(s) and that of the
Table 2. Experimental conversion factors used in this study

\begin{tabular}{lccc}
\hline \hline Method & Device & Target GM & $C_{\mathrm{f}}{ }^{\mathrm{a}}$ \\
\hline MON810 construct sp. & 7700 & MON810 & $0.38^{\mathrm{b}}$ \\
\hline GA21 construct sp. & 7700 & GA21 & $2.01^{\mathrm{b}}$ \\
\hline \multirow{2}{*}{ Duplex } & 7900 & MON810 & 0.33 \\
\cline { 2 - 3 } & & GA21 & 0.50 \\
\cline { 2 - 3 } & 7500 & MON810 & 0.30 \\
\cline { 3 - 4 } & & GA21 & 0.45 \\
\hline
\end{tabular}

${ }^{a}$ Conversion factors used in this study were culculated from means of measurements of ten lots with three replications.

b These factors were referred to footnote $* 3$.

SSIIb segment were performed on the same PCR run. The ratios of the GM-specific sequence to the taxonspecific sequence in the DNA extracted from each genuine GM seed were defined as conversion factors $\left(C_{\mathrm{f}}\right)$. We calculated the experimental conversion factors for each of the methods and real-time PCR devices, respectively, and those obtained in this study are listed in Table 2.

For comparison, we analyzed the same samples by means of the construct-specific, simplex real-time PCR methods for MON810 maize or to GA21 maize performed with the 7700 real-time PCR system (Applied Biosystems). These methods employed the constructspecific primer pairs (Table 1) used in our established methods $^{12)}$ and GM Maize Detection Plasmid Set - ColE1/TE- (Nippon Gene Co., Ltd., Toyama, Japan) for the analytical calibration. An improved SSIIb primer pair (SSIIb03 $-5^{\prime}$ and $-3^{\prime}$ ) described elsewhere ${ }^{16}$ ) was used for the construct-specific real-time PCR as well as for the duplex real-time PCR (Table 1).

\section{Analytes for single laboratory evaluation}

Four sorts of simulated mixtures of MON810 as targets for the P35S quantitation and GA21 with different commingled levels in a non-GM background, i.e. $0.5 \%(\mathrm{w} / \mathrm{w}), 1 \%(\mathrm{w} / \mathrm{w}), 5 \%(\mathrm{w} / \mathrm{w})$ and $10 \%(\mathrm{w} / \mathrm{w})$ each, were prepared as described in our previous report ${ }^{13)}$. Each level of mixture was prepared on a $100 \mathrm{~g}$ or $200 \mathrm{~g}$ scale, and was divided into aliquots of about $1 \mathrm{~g}$ (about 100 or 200 independent packets were prepared). The homogeneity of each simulated mixture sample was confirmed by one-way ANOVA tests ${ }^{12)}$. Ten packets chosen at random from each commingled level of samples were subjected to quantitation with the established methods, and each measurement was performed twice for each sample. Table 3 shows the results of one-way ANOVA tests of the logit-transformed means for each duplicate quantitation. These results showed that the between-lot variations were not different from the within-lot variations in each sort of simulated mixture. Thus, the simulated mixtures used in this study were found to be sufficiently homogenous within each sort. 
Table 3. Homogeneity of the simulated mixtures ${ }^{a}$

\begin{tabular}{|c|c|c|c|c|c|c|c|}
\hline \multirow{2}{*}{ Sample } & \multirow{2}{*}{ Target GMO } & \multirow{2}{*}{ Mixing level, \% } & \multirow{2}{*}{ Measured mean, \% } & \multicolumn{2}{|c|}{$95 \%$ Confidence limit ${ }^{b}$} & \multirow{2}{*}{$F$-value } & \multirow{2}{*}{$p$-value } \\
\hline & & & & Lower, \% & Upper, \% & & \\
\hline \multirow[t]{2}{*}{$\mathrm{A}$} & MON810 & 0.5 & 0.48 & 0.44 & 0.51 & 0.38 & 0.92 \\
\hline & GA21 & 0.5 & 0.50 & 0.47 & 0.53 & 0.88 & 0.57 \\
\hline \multirow[t]{2}{*}{ B } & MON810 & 1 & 1.17 & 1.13 & 1.22 & 2.7 & 0.067 \\
\hline & GA21 & 1 & 1.09 & 1.05 & 1.14 & 1.2 & 0.40 \\
\hline \multirow[t]{2}{*}{$\mathrm{C}$} & MON810 & 5 & 4.47 & 4.32 & 4.63 & 0.47 & 0.86 \\
\hline & GA21 & 5 & 4.84 & 4.67 & 5.02 & 2.7 & 0.070 \\
\hline \multirow[t]{2}{*}{$\mathrm{D}$} & MON810 & 10 & 9.21 & 8.83 & 9.60 & 0.29 & 0.96 \\
\hline & GA21 & 10 & 9.64 & 9.28 & 10.01 & 0.78 & 0.64 \\
\hline
\end{tabular}

a Measurements of ten lots with two replications were transformed using the logit transformation and were analyzed by one-way ANOVA.

${ }^{\mathrm{b}}$ Means and 95\% confidence limits were calculated based on logistic values and transformed using the inverse logit transformation.

\section{Results and Discussion}

\section{Designing of duplex real-time PCR}

As the targets of this method, we chose the P35S and an event-specific segment for GA21. The CaMV35S promoter has been found in a very wide range of GM crops, and this has led to the development of many GMO detection methods targeting this segment with real-time PCR technology ${ }^{12), 16)-18)}$. We also chose an event-specific segment for GA21 as a target of this method ${ }^{13)}$ because GA 21 maize does not contain a P35S segment, and the P35 $\mathrm{S}$ and the GA21 maize event-specific (GA21e) segment do not overlap in any GM maize. We could have chosen the P35S and the terminator of the nopalin synthase gene (TNOS), which is the most popular terminator used in GM crops. This may be able to detect a wider range of GM maize. On the other hand, there are many events which have both the P35S segment and the TNOS segment. Thus, the method targeting both of the segments would tend to over-estimate the GM content more than the duplex real-time PCR method developed in this study.

The PCR conditions for these methods have been optimized under the simplex real-time PCR conditions. In this study, we first assembled these simplex methods to design a duplex real-time PCR method and examined its performance. For this purpose, we constructed a duplex real-time PCR by assembling two real-time PCR methods for P35S and GA21e. As shown in Fig. 2, the combined primer pairs for P35S and GA21e gave specific amplification for the relevant GM maize and GM soybean, and no amplification was observed in the reactions of non-GM crops. These primer pairs were therefore chosen for the design of the duplex real-time PCR method.

TaqMan probes for their amplification products were also designed, and the fluorescent modifications were carefully considered for the duplex real-time PCR quantitation. In this study, we found a combination consisting of the P35S-TaqFB probe modified with 5carboxyfluorescein (FAM) at the $5^{\prime}$-end and with Black
Hole Quencher 1 (BHQ1) at the $3^{\prime}$-end, and the GA21 es-TaqHB probe modified with 6 -carboxy-2', 4, $4^{\prime}, 5^{\prime}, 7,7^{\prime}$ hexachlorofluorescein (HEX) at the $5^{\prime}$-end and with BHQ1 at the 3 '-end (Table 1). Quencher molecules without fluorescence emission are preferable for multiplex real-time PCR methods, because they reduce the risk of interference of fluorescence emission caused by multiple reporters. In fact, other types of probe are also available, such as MGB probe with non-fluorescent quencher (DABCYL). However, this type of probe was not convertible with the currently used probes and required redesign of the oligonucleotide sequences of the probes. Thus, we chose BHQ1 for the quencher molecule. For reporter molecules, we examined six kinds of fluorescent substances and their combinations. We concluded that a combination of FAM as the reporter of the P35S probe and HEX as that of the GA21e probe was optimum for this method (data not shown). VIC also showed good performance, but we chose BHQ1 because of a commercial reason.

\section{Construction of calibrant plasmid and its performance in duplex real-time PCR}

We have already developed some real-time PCR methods for the quantitation of GM contents, and plasmid DNAs containing tandemly ligated GM-specific DNA segments and taxon-specific DNA segments have been used as analytical calibrators ${ }^{12}$. In this study, we constructed a new calibrant plasmid for the duplex PCR method. To construct it, we had to ensure that unintended amplification between the insertions in the plasmid did not occur. Figure 1 shows the schematic diagram of the calibrant plasmid, designated as pSCM. The pSCM plasmid has three DNA segments; $101 \mathrm{bp}$ of the P35S segment, $111 \mathrm{bp}$ of the GA21e segment, and $151 \mathrm{bp}$ of the SSIIb segment. The inserted sites were mutually separated by more than a $1 \mathrm{~kb}$ interval, and after digestion, the calibrant plasmid was linearized for use (Fig. 1). We confirmed that no unintended amplification was observed with the pSCM plasmid under both the qualitative and quantitative PCR conditions (Figs. 2 
and 3).

The duplex and the simplex real-time PCRs were performed with the pSCM plasmids diluted to a concentration ranging from 20 to 250,000 copies per reaction. Figure 3 shows the amplification plots of the duplex real-time PCR (B, D), and the simplex real-time PCRs (A, C) which were the components of the duplex real-time PCR. Each detection plot for P35S (E, F) and GA21e (G, $\mathrm{H})$ demonstrated correlated amplification with the copy

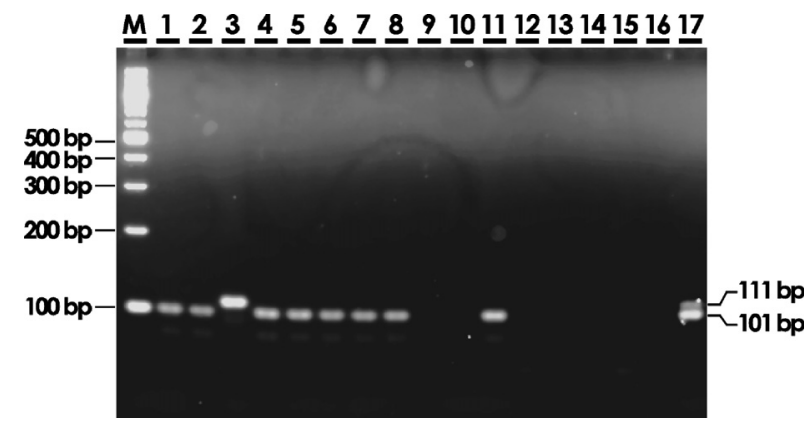

Fig. 2. Specificity of duplex PCR

The qualitative PCR was performed with the combination of primer pairs developed in this study. $111 \mathrm{bp}$ and $101 \mathrm{bp}$ bands were amplification products corresponding to GA21e and P35S segments, respectively. Lanes 1-8, amplification of DNAs extracted from the seeds of NK603, Event176, T25, GA21, MON863, MON 810, TC1507 and Bt11, respectively; lane 9, non-GM maize; lane 10, non-GM soy; lane 11 , Roundup Ready ${ }^{\circledR}$ soy; lane 12 , rice; lane 13 , wheat; and lane 14, barley. Lanes 15 and 16 are the negative controls (no template and no primers, respectively). Lane 17 is an amplification of pSCM plasmid. Lane M shows $100 \mathrm{bp}$ ladder size standards. Each electrophoresis was performed on $3 \%$ agarose gel. number of its target segment, and the efficiency of PCR amplification in the duplex real-time PCR was almost equivalent to that in the simplex PCRs (Fig. 3). In addition, we performed the duplex real-time PCR using two types of real-time PCR devices with different fluorescence detection mechanisms. No significant optical crosstalk between the detection channels was observed on either device (data not shown). Thus, we concluded that the duplex real-time PCR would be a good candidate for a routine method for the screening of agricultural crops.

\section{Precision of duplex real-time PCR method}

To evaluate the precision of the duplex real-time PCR method, a single-laboratory evaluation experiment was designed based on the harmonized guidelines of IUPAC, ISO, and $\mathrm{AOAC}^{20)}$, and conducted. In this study, MON 810 was chosen as a representative of GM maize events containing the P35S segment, because it has been widely grown and has only one P35S segment per GM haploid. Then, we prepared simulated samples containing two events, MON810 and GA21, in four different GM commingle levels $(0.5 \%, 1 \%, 5 \%$, and $10 \%)$. These simulated samples were analyzed by the established real-time PCR methods ${ }^{12)}$, and by the newly developed duplex real-time PCR method (Tables 4 and 5).

In this study, we employed the 7900 real-time PCR system as one of the analytical devices for the duplex real-time PCR method, which is a successor of the 7700 real-time PCR system used previously ${ }^{12)}$. In addition, we also analyzed the same samples by the duplex real-time PCR method with the 7500 real-time PCR system, which has a different optical system than the 7900 system. By the duplex real-time PCR method with the 7900 real-time PCR system, the relative standard deviation (RSD) scores ranged from $2.8 \%$ to $8.2 \%$ for $\mathrm{MON}$
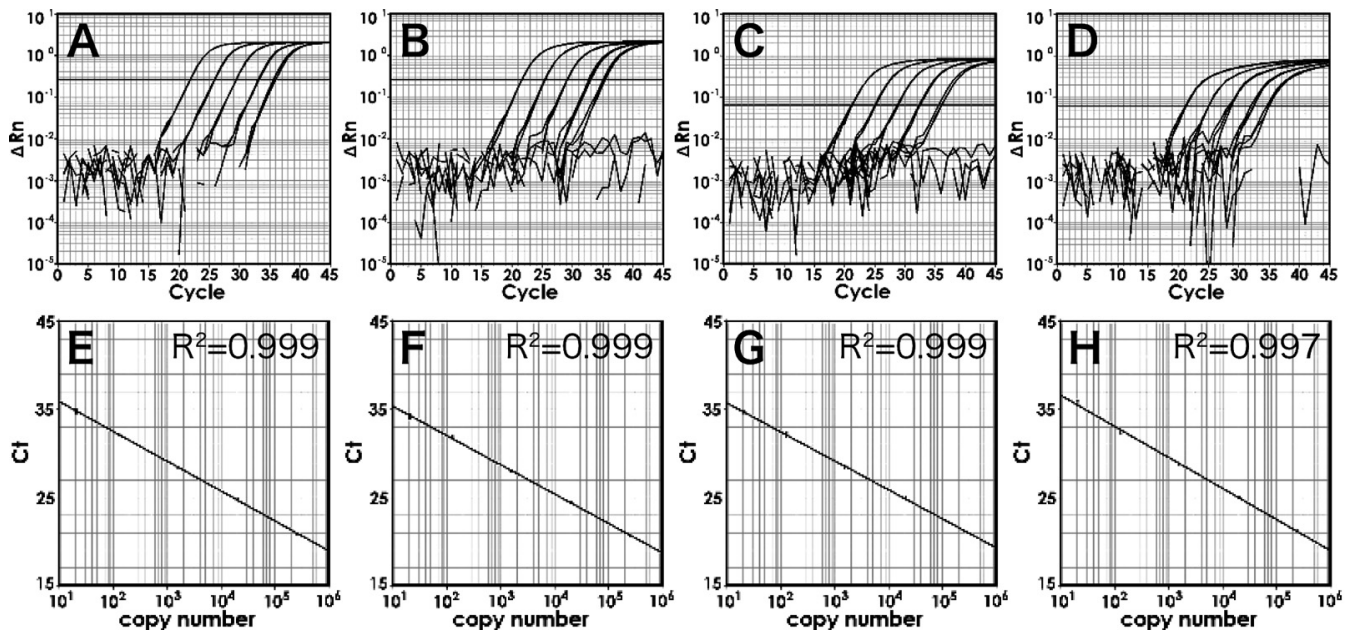

Fig. 3. Amplification plots for dilution series of pSCM plasmid and corresponding standard curves

Typical patterns of amplification plots of a P35S segment are shown in A and B, and those for a GA21 event-specific segment are shown in $\mathrm{C}$ and D. Each amplification was performed using the individual simplex real-time PCRs (A, C) or the duplex real-time PCR (B, D) with a 7900 real-time PCR system. The respective calibration curves are shown in the panels below. The correlation factors of the standard curves are indicated at the upper-right corners. 
Table 4. Trueness and precision statistics of measurements of the estimated method ${ }^{a}$

\begin{tabular}{|c|c|c|c|c|c|c|}
\hline \multirow{2}{*}{ Sample } & \multirow{2}{*}{ Target GMO } & \multirow{2}{*}{ Mixing level, \% } & \multicolumn{2}{|c|}{ Trueness } & \multicolumn{2}{|c|}{ Precision } \\
\hline & & & Measured mean, \% & Bias, relative $\%$ & $\mathrm{SD}^{\mathrm{b}}$ & $\mathrm{RSD}^{\mathrm{c}}$ \\
\hline \multirow[t]{2}{*}{ non-GMO } & MON810 & 0 & 0.00 & nd & 0.00 & nd \\
\hline & $\mathrm{GA} 21^{\mathrm{e}}$ & 0 & 0.00 & nd & 0.00 & nd \\
\hline \multirow[t]{2}{*}{$\mathrm{A}$} & MON810 & 0.5 & 0.45 & -0.090 & 0.042 & 9.2 \\
\hline & GA21 & 0.5 & 0.48 & -0.040 & 0.042 & 8.8 \\
\hline \multirow[t]{2}{*}{ B } & MON810 & 1 & 1.17 & 0.17 & 0.06 & 5.4 \\
\hline & GA21 & 1 & 1.11 & 0.11 & 0.052 & 4.7 \\
\hline \multirow[t]{2}{*}{$\mathrm{C}$} & MON810 & 5 & 4.61 & -0.078 & 0.19 & 4.2 \\
\hline & GA21 & 5 & 4.79 & -0.041 & 0.27 & 5.7 \\
\hline \multirow[t]{2}{*}{$\mathrm{D}$} & MON810 & 10 & 9.63 & -0.037 & 0.43 & 4.5 \\
\hline & GA21 & 10 & 9.40 & -0.060 & 0.49 & 5.2 \\
\hline
\end{tabular}

${ }^{a}$ Each experiment was performed with ten independent packets. Each real-time PCR was performed with three wells replication, and repeated twice on independent PCR runs. Means of those measurements were used for statistical analyses.

${ }^{\mathrm{b}} \mathrm{SD}$ : Standard deviation

${ }^{\mathrm{c}} \mathrm{RSD}$ : Relative standard deviation

${ }^{d}$ Analyses were performed by the construct-specific real-time PCR method for MON810 maize ${ }^{12}$.

${ }^{\mathrm{e}}$ Analyses were performed by the construct-specific real-time PCR method for GA21 maize ${ }^{12)}$.

Table 5. Trueness and precision statistics of measurements of the duplex real-time PCR methods

\begin{tabular}{|c|c|c|c|c|c|c|c|}
\hline \multirow{2}{*}{ Instrument } & \multirow{2}{*}{ Sample } & \multirow{2}{*}{ Target GMO } & \multirow{2}{*}{ Mixing level, \% } & \multicolumn{2}{|c|}{ Trueness } & \multicolumn{2}{|c|}{ Precision } \\
\hline & & & & Measured mean, \% & Bias, relative $\%$ & $\mathrm{SD}^{\mathrm{b}}$ & $\mathrm{RSD}^{\mathrm{c}}$ \\
\hline \multirow[t]{10}{*}{7900} & non-GMO & MON810 & 0 & 0.00 & nd & 0.00 & nd \\
\hline & & $\mathrm{GA} 21^{\mathrm{d}}$ & 0 & 0.00 & nd & 0.00 & nd \\
\hline & $\mathrm{A}$ & MON810 & 0.5 & 0.51 & 0.028 & 0.037 & 7.3 \\
\hline & & GA21 & 0.5 & 0.52 & 0.032 & 0.046 & 8.9 \\
\hline & B & MON810 & 1 & 1.03 & 0.026 & 0.084 & 8.2 \\
\hline & & GA21 & 1 & 0.93 & -0.074 & 0.062 & 6.7 \\
\hline & $\mathrm{C}$ & MON810 & 5 & 5.44 & 0.088 & 0.24 & 4.3 \\
\hline & & GA21 & 5 & 4.70 & -0.059 & 0.13 & 2.8 \\
\hline & $\mathrm{D}$ & MON810 & 10 & 11.06 & 0.11 & 0.31 & 2.8 \\
\hline & & GA21 & 10 & 9.59 & -0.041 & 0.36 & 3.7 \\
\hline \multirow[t]{10}{*}{7500} & non-GMO & MON810 & 0 & 0.00 & nd & 0.00 & nd \\
\hline & & GA21 & 0 & 0.00 & nd & 0.00 & nd \\
\hline & A & MON810 & 0.5 & 0.52 & 0.045 & 0.053 & 10.1 \\
\hline & & GA21 & 0.5 & 0.44 & -0.12 & 0.036 & 8.1 \\
\hline & B & MON810 & 1 & 1.03 & 0.025 & 0.066 & 6.4 \\
\hline & & GA21 & 1 & 0.87 & -0.13 & 0.075 & 8.7 \\
\hline & $\mathrm{C}$ & MON810 & 5 & 4.65 & -0.071 & 0.40 & 8.7 \\
\hline & & GA21 & 5 & 3.95 & -0.21 & 0.33 & 8.4 \\
\hline & $\mathrm{D}$ & MON810 & 10 & 10.01 & 0.0012 & 0.88 & 8.8 \\
\hline & & GA21 & 10 & 8.61 & -0.14 & 0.55 & 6.4 \\
\hline
\end{tabular}

${ }^{a}$ Each experiment was performed with ten independent packets. Each real-time PCR was performed with three wells replication, and repeated twice on independent PCR runs. Means of those measurements were used for statistical analyses.

${ }^{\mathrm{b}} \mathrm{SD}$ : Standard deviation

${ }^{\mathrm{c}} \mathrm{RSD}$ : Relative standard deviation

d GM-specific segment was analyzed by the duplex real-time PCR.

810 and from 2.8\% to $8.9 \%$ for GA21 (Table 5). Comparison of these scores with those obtained by the established methods suggested that the precision of the duplex real-time PCR method was almost the same as those of the established methods (Tables 4 and 5). As for results obtained with the 7500 real-time PCR system, 
the RSD scores were generally higher than those obtained with the 7900 real-time PCR system, but most of them were found to be below 10\% (Table 5). The general analytical uncertainty of the quantitative PCR method was found to be around $25 \%{ }^{4}$. These results demonstrated that the precision of the developed method satisfied the criteria of quantitative analysis by the real-time PCR method at the tested range of 0.5 to $10 \%$. The result of single-laboratory evaluation suggested that the limit of quantitation (LOQ) of the duplex real-time PCR method is lower than 0.5\% for both MON810 and GA21 maize (Table 5). This LOQ is the same as that seen in our previous real-time PCR methods, which have a GM-specific amplification site per GM haploid ${ }^{15)}$. Since the regulatory threshold level for obligatory GM labeling is 5\% in Japan, the LOQ is sufficient for a regulatory analytical method. Thus, although future interlaboratory validation is needed, the current results indicate that the duplex real-time PCR would be a good candidate for a routine method for the screening of agricultural crops. Further investigations are necessary, regarding the rapidly increasing stacked varieties.

\section{Conclusion}

In this study, we developed a duplex real-time PCR that could quantitatively detect not only a P35S segment but also an event-specific segment for a Roundup Ready maize, GA21. The method using the duplex realtime PCR quantified the contents of GM maize with P35S and GA21 simultaneously, and their sum represented the total content of GM maize in the sample. The result of a single-laboratory evaluation demonstrated that the precision of this method is almost the same as those of the established methods. In addition, this method will reduce both the cost and time requirement of routine GMO analysis by half. Consequently, the duplex real-time PCR method was considered to be a good candidate for a routine screening method for GM maize commingled in agricultural products.

\section{Acknowledgements}

We would like to thank E. I. du Pont de Nemours and Company (Wilmington, DE, USA), Monsanto Company (St. Louis, MO, USA), and Syngenta Seeds AG (Basel, Switzerland) for their provision of the GM crop seeds. This study was supported in part by a grant from the Ministry of Agriculture, Forestry and Fisheries of Japan for the Research Project, "Assurance of Safe Use of Genetically Modified Organisms”, and also by a grant from the Ministry of Health, Labor and Welfare of Japan.

\section{References}

1) James, C. Global status of commercialized biotech/GM crops 2007. ISAAA Briefs, Vol. 37, ISAAA, Ithaca, NY, 2007.

2) Hino, A. Safety assessment and public concerns for genetically modified food products: The Japanese experi- ence. Toxicol. Pathol., 30, 126-128 (2002).

3) Ahmed, F.E. Detection of genetically modified organisms in foods. Trends Biotechnol., 20, 215-223 (2002).

4) Holst-Jensen, A., Ronning, S. B., Lovseth, A., Berdal, K. G. PCR technology for screening and quantification of genetically modified organisms (GMOs). Anal. Bioanal. Chem., 375, 985-993 (2003).

5) Rodoríguez-Lázaro, D., Lombard, B., Smith, H., Rzezutka, A., D'agostino, M., Helmuth, R., Schroeter, A., Malorny, B., Miko, A., Guerra, B., Davison, J., Kobilinsky, A., Hernándes, M., Bertheau, Y., Cook, N. Trends in analytical methodology in food safety and quality: Monitoring microorganisms and genetically modified organisms. Trands Food Sci. Tech., 18, 306-319 (2007).

6) Matsuoka, T., Kawashima, Y., Akiyama, H., Miura, H., Goda, Y., Kusakabe, Y., Isshiki, K., Toyoda, M., Hino, A. A method of detecting recombinant DNAs from four lines of genetically modified maize. J. Food Hyg. Soc. Japan., 41, 137-143 (2000).

7) Matsuoka, T., Kuribara, H., Takubo, K., Akiyama, H., Miura, H., Goda, Y., Kusakabe, Y., Isshiki, K., Toyoda, M., Hino, A. Detection of recombinant DNA segments introduced to genetically modified maize (Zea mays). J. Agric. Food Chem., 50, 2100-2109 (2002).

8) Watanabe, T., Kuribara, H., Mishima, T., Kikuchi, H., Kodama, T., Futo, S., Kasama, K., Toyota, A., Nouno, M., Saita, A., Takahashi, K., Hino, A., Akiyama, H., Maitani, T. New qualitative detection methods of genetically modified potatoes. Biol. Pharm. Bull., 27, 1333-1339 (2004).

9) Onishi, M., Matsuoka, T., Kodama, T., Kashiwaba, K., Futo, S., Akiyama, H., Maitani, T., Furui, S., Oguchi, T., Hino, A. Development of a multiplex polymerase chain reaction method for simultaneous detection of eight events of genetically modified maize. J. Agric. Food Chem., 53, 9713-9721 (2005).

10) Watanabe, T., Tokishita, S., Spiegelhalter, F., Furui, S., Kitta, K., Hino, A., Matsuda, R., Akiyama, H., Maitani, T. Development and evaluation of event-specific qualitative PCR methods for genetically modified Bt10 maize. J. Agric. Food Chem., 55, 1274-1279 (2007).

11) Watanabe, T., Shiramasa, Y., Furui, S., Kitta, K., Minegishi, Y., Akiyama, H., Maitani, T. Development and evaluation of qualitative detection methods for unapproved genetically modified rice (LLrice). J. Food Hyg. Soc. Japan., 48, 170-178 (2007).

12) Kuribara, H., Shindo, Y., Matsuoka, T., Takubo, K., Futo, S., Aoki, N., Hirao, T., Akiyama, H., Goda, Y., Toyoda, M., Hino, A. Novel reference molecules for quantitation of genetically modified maize and soybean. J. AOAC Int., 85, 1077-1089 (2002).

13) Oguchi, T., Onishi, M., Chikagawa, Y., Minegishi, Y., Kodama, T., Akiyama, H., Ohno, Y., Futo, S., Hino, A., Furui, S., Kitta, K. Development of event-specific quantitation method for GA21 maize, which is a GM event without CaMV35S promoter. J. Food Hyg. Soc. Japan., 49, 16-22 (2008).

14) Akiyama, H., Watanabe, T., Wakabayashi, K., Nakade, S., Yasui, S., Sakata, K., Chiba, R., Spiegelhalter, F., Hino, A., Maitani, T. Quantitative detection system for maize sample containing combined-trait genetically modified maize. Anal. Chem., 77, 7421-7428 (2005).

15) Shindo, Y., Kuribara, H., Matsuoka, T., Futo, S., Sawada, C., Shono, J., Akiyama, H., Goda, Y., Toyoda, M., Hino, A. Validation of real-time PCR analyses for line-specific quantitation of genetically modified maize and soybean 
using new reference molecules. J. AOAC Int., 85, 11191126 (2002).

16) Yoshimura, T., Kuribara, H., Matsuoka, T., Kodama, T., Iida, M., Watanabe, T., Akiyama, H., Maitani, T., Furui, S., Hino, A. Applicability of the quantification of genetically modified organisms to foods processed from maize and soy. J. Agric. Food Chem., 53, 2052-2059 (2005).

17) Fernandez, S., Charles-Delobel, C., Geldreich, A., Berthier, G., Boyer, F., Collonnier, C., Coue-Philippe, G., Diolez, A., Duplan, M. N., Kebdani, N., Romaniuk, M., Feinberg, M., Bertheau, Y. Quantification of the 35S promoter in DNA extracts from genetically modified organisms using realtime polymerase chain reaction and specificity assessment on various genetically modified organisms, Part I:
Operating procedure. J. AOAC Int., 88, 547-557 (2005).

18) Cankar, K., Ravnikar, M., Zel, J., Gruden, K., Toplak, N. Real-time polymerase chain reaction detection of cauliflower mosaic virus to complement the $35 \mathrm{~S}$ screening Assay for genetically modified organisms. J. AOAC Int., 88, 814-822 (2005).

19) Cankar, K., Chauvensy-Ancel, V., Fortabat, M.N., Gruden, K., Kobilinsky, A., Zel, J., Bertheau, Y. Detection of nonauthorized genetically modified organisms using differential quantitative polymerase chain reaction: Application to 35S in maize. Anal Biochem., 376, 189-199 (2008).

20) Thompson, M., Ellison, S. L. R., Wood, R. Harmonized guidelines for single-laboratory validation of methods of analysis. Pure Appl. Chem., 74, 835-855 (2002). 